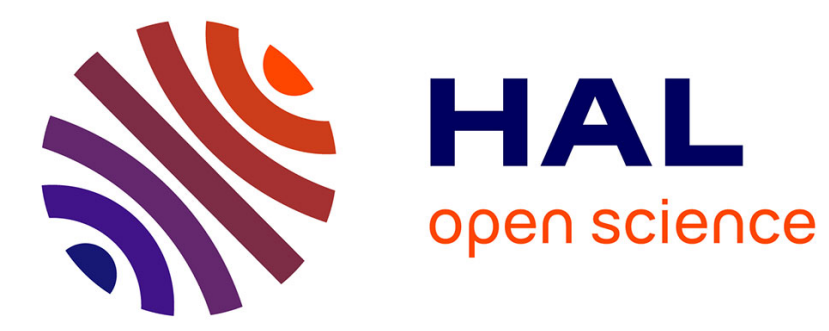

\title{
Do product category and consumers' motivations profiles matter regarding counterfeiting?
}

André Le Roux, Marinette Thébault, Yves Roy

\section{To cite this version:}

André Le Roux, Marinette Thébault, Yves Roy. Do product category and consumers' motivations profiles matter regarding counterfeiting?. Journal of Product and Brand Management, 2019, 10.1108/JPBM-06-2018-1923 . hal-02396896

\section{HAL Id: hal-02396896 https://hal.science/hal-02396896}

Submitted on 6 Dec 2019

HAL is a multi-disciplinary open access archive for the deposit and dissemination of scientific research documents, whether they are published or not. The documents may come from teaching and research institutions in France or abroad, or from public or private research centers.
L'archive ouverte pluridisciplinaire HAL, est destinée au dépôt et à la diffusion de documents scientifiques de niveau recherche, publiés ou non, émanant des établissements d'enseignement et de recherche français ou étrangers, des laboratoires publics ou privés. 
Do product category and consumers' motivations profiles matter regarding counterfeiting?

Journal of Product and Brand Management, May 2019

LE ROUX André

aleroux@poitiers.iae-france.fr

THEBAULT Marinette

mthebault@poitiers.iae-france.fr

ROY Yves

yr@poitiers.iae-france.fr

Institut d'Administration des Entreprises (IAE),

Université de Poitiers,

CEntre de REcherche en GEstion (CEREGE) EA 1722

20 rue Guillaume VII le Troubadour, Bât.E1 TSA 61116

86073 Poitiers Cedex 9, France 


\section{Structured Abstract:}

Purpose: This research explores the impact of product category and consumers' motivations profiles on the determinants of consumers' preferences and purchase intentions of counterfeits and genuine, through manipulation of product attributes and purchase situations.

Design/Methodology: The research relies on an experimental design involving a questionnaire on a convenience sample with two parts: a trade-off model manipulating three attributes: Product type (genuine $v s$ counterfeit), Price (high $v s$ low), Place of purchase (regular shop, Internet, market) in two product categories and a scale measuring motivations to purchase counterfeits. Ranking and purchase intentions are analyzed using conjoint analysis and Generalized Linear Mixed Model (GLMM).

Findings: Ranking reveals a dominant pattern of consumer behavior regarding counterfeiting: Product type, Price and Place of purchase. Product category has a moderating effect on choice criteria: relative importance of Place of purchase and Price varies according Product category. Consumers' motivations profiles have also a moderating effect on consumer behavior. Some profiles are more receptive to copies. Consumers' profiles exhibit different hierarchies of purchase criteria, and may change them depending upon product category.

\section{Originality/value:}

Results challenge literature on the dominant role of price among choice criteria. Price alone cannot determine a counterfeit purchase. It is the interaction of Price, Place of purchase or Product type that explains such a behavior. Product category matters: price and place of purchase importance cannot be considered without accounting for product category. Consumers' motivations profile matters. Consumers are not homogeneous face to counterfeits.

Key Words: Counterfeit, Counterfeiting, Consumers' motivations profiles, Product category, Product attributes, Purchase situation, Experimental plan, Conjoint analysis, Generalized Linear Mixed Models

Article Classification: Research paper 


\section{Do product category and consumers' motivations profiles matter regarding counterfeiting? \\ André LE ROUX, Marinette THEBAULT, Yves ROY}

\section{Introduction}

According to OECD/EUIPO (2016), imports of counterfeit and pirated goods are worth nearly half a trillion dollars a year and represent around $2.5 \%$ of global imports. Up to $5 \%$ of goods imported into the European Union are fakes. According to a survey from VDMA, a German association that represents companies in the mechanical and systems engineering industry, $71 \%$ of machine and plant manufacturers in Germany are affected by product or brand piracy. The estimated damage amounts to 7.3 billion euros per year (VDMA, 2018). Counterfeiting undermines the economy through job losses. For companies, counterfeiting results in reduced turnover, lower return on investment and innovation, added costs related to legal actions and intellectual property rights (IPR) protective devices development, and leads to significant damage to brand equity. From a more global well-being standpoint, counterfeiting represents a threat for consumers as well as citizens through increased risks related to faulty or fraudulent products and triggers defiance toward products and corporations.

Academic research on counterfeiting has addressed various topics. A first stream of research focuses on the definition of counterfeiting and its consequences on original brands and on original brand owners (Bamossy and Scammon, 1985; Yoo and Lee, 2005; Commuri, 2009; Romani et al., 2012; Baghi et al., 2016; Le Roux et al., 2016a). Another stream explores the determinants of counterfeit products purchase (Ang et al., 2001; Gistri et al., 2009; Wilcox et al., 2009; Bian and Moutinho, 2011, Viot et al., 2014). A third stream attempts to model consumer behavior regarding counterfeiting using theoretical frameworks such as the Theory of Reasoned Action or the Theory of Planned Behavior (Penz and Stöttinger, 2005; De Matos et al. 2007). A fourth stream addresses the managerial response to counterfeiting (Chaudhry et al., 2005; Staake et al., 2009; Cesareo and Stöttinger, 2015). Eisend and Schucher-Güler (2006), Zaichkowsky (2006), Lee and Yoo (2009), Staake et al. (2009), Cesareo (2016) provided a comprehensive cover of the topic of counterfeiting.

Despite important academic contributions, little research on the determinants of counterfeit purchase has addressed product category effect. The purpose of this study is to explore the impact of product category on the determinants of consumers' preferences and purchase intentions of counterfeits and genuine. Most research considers consumers of 
counterfeits as a homogeneous population, while few studies suggest the existence of subpopulations differing in their motivations, general attitude or purchase intentions toward counterfeiting. Our research explores if accounting for consumers' motivations profiles modifies the role and the importance of the determinants of consumers' preferences and purchase intentions.

\section{Literature review}

\section{Defining counterfeiting}

Counterfeiting is a legal concept defined as "the act of producing or selling a product containing an intentional and calculated reproduction of a genuine trademark. A 'counterfeit mark' is identical to or substantially indistinguishable from a genuine mark" (McCarthy, 2004). From a marketing standpoint, "Any unauthorized manufacturing of goods whose special characteristics are protected as intellectual property rights (trademark, patent, and copyrights) constitutes product counterfeiting" (Cordell et al., 1996).

Bamossy and Scammon (1985) define two types of counterfeiting: deceptive and nondeceptive counterfeiting. Deceptive counterfeiting occurs when a consumer buys a fake, believing that it is an original. Deception is due to similarity between the genuine item and the copy, therefore the consumer can be considered a victim. Non-deceptive counterfeiting means that a consumer knowingly and willingly purchases a fake product. Cues such as price, place of purchase, product quality, or the seller's explicit information leave no doubt about the illegal nature of the purchased item (Bloch et al., 1993; Gentry et al., 2001, 2006). In that case, the purchase is a deliberate behavior and the consumer can be considered as an accomplice to counterfeiters (Bloch et al., 1993). This research focuses specifically on nondeceptive counterfeits' purchase.

\section{Product categories effect}

Most surveys either do not account for a product category or focus on a single product class. According to Ceseareo (2016), "out of the 572 articles analyzed, 162 articles did not make a direct reference to any specific industry, discussing counterfeit and/or pirated goods in general". When a product is studied, research focuses on consumer goods such as knit sportshirts (Bloch et al., 1993), pirated music CDs (Ang et al., 2001) or sunglasses (Veloutsou and Bian, 2008).

Few studies encompass different products. D'Astous and Gargouri (2001) explore bread, shampoo, polo shirts and sunglasses. They examine the impact of goodness of 
imitation, brand store image and presence of the original brand on consumer evaluation of these products. Yoo and Lee (2005) investigate if counterfeits function as a promotion for genuine items on five luxury goods: handbags, designer shoes, apparel, sunglasses and jewelry. Le Roux et al. (2016a) explore the impact of varying degrees of imitations in terms of brand name and product appearance on consumer evaluation of four products: perfume, spirits, energy drinks and electronics. Le Roux et al. (2016b) study the impact of brand typicality on brand evaluation and categorization of counterfeits and imitations for the same four products tested.

Even if these studies do not address specifically the effect of product category on consumer evaluation, results show different reactions according to products. For example, D'Astous and Gargouri (2001) observe a positive impact of store image on consumer evaluations of luxury product imitations (polo and sunglasses). For convenience products (bread only), such an effect is observed only when the original brand is absent. When the original brand is present, consumer evaluations are more negative if the copy is offered in a good image store rather in a poor image store. According to Yoo and Lee (2005), consumers of counterfeits prefer counterfeits more than non-consumers of counterfeits for all products except sunglasses. Consumers of counterfeits prefer genuine items more than non-consumers of counterfeits for handbags, designer shoes, and jewelry, but not for apparel and sunglasses. Le Roux et al. (2016a) show that consumers react to brand name and product appearance manipulations: deviations from the original brand name and product appearance are poorly evaluated and rejected as counterfeits. However, in some product categories (spirits and perfumes), some deviations from the genuine brand name and product appearance are more acceptable.

These few results highlight that regarding consumers' reactions to counterfeiting, product category matters. The objective of our research is to study specifically the moderating effect of product category on the determinants of consumers' preferences and purchase intentions of counterfeits and genuine.

\section{Determinants of counterfeits purchase}

In their review of the determinants and moderators of the volitional purchase of counterfeit products, Eisend and Schucher-Güler (2006) identify four categories of determinants: person, product, social and cultural context, and purchase situation.

Person or individual characteristics encompass demographics, such as age, income, educational level (Bloch et al., 1993; Penz and Stöttinger, 2005; Cheung and Prendergast, 
2006; Hamelin et al., 2013) and psychographics. The psychographic variables include personality traits, such as materialism, novelty seeking, value consciousness, integrity, conformity, personal gratification, status consumption; social factors such as information susceptibility, normative susceptibility, collectivism; motivations such as desire for luxury brands, hedonistic motivation, perceived risk, and revenge on big business (Ang et al., 2001; Penz and Stöttinger, 2005; Cheung and Prendergast, 2006; Veloutsou and Bian, 2008; Lee and Yoo; 2009, Phau and Teah, 2009; Geiger-Oneto et al.; 2013; Hamelin et al., 2013; Viot et al., 2014; Bian et al., 2016). Personal or individual characteristics have been extensively studied, especially personality traits and motivations. Eisend (2017) provided a review of the topic through a meta-analysis.

Product-related characteristics comprise product attributes such as price, brand image, reliability, durability, physical appearance, quality, perceived fashion content, functional and hedonic or symbolic benefits (Tom et al., 1998; D'Astous and Gargouri, 2001; Harvey and Walls, 2003; Yoo and Lee, 2005; Bian and Moutinho, 2009; Hamelin et al., 2013; Le Roux et $a l ., 2016 \mathrm{a})$. In the literature, price is considered as a dominant reason for buying counterfeit (Bloch et al., 1993; Tom et al., 1998; Prendergast et al. 2002; Harvey and Walls, 2003; Lee and Yoo, 2009). Several authors identify a positive relationship between a low price of a copy and the decision to purchase counterfeits (Harvey and Walls 2003; Gentry et al., 2006; Staake and Fleisch, 2008; Lee and Yoo, 2009). In addition, a higher genuine price renders more likely the purchase of a counterfeit (Moores and Dhillon, 2000; Lee and Yoo, 2009). Schlegelmich and Stöttinger (1999) pinpoint that a 40\% price differential between a genuine and a copy has a negative effect on purchase intention of originals.

Few studies account for variations or manipulations in product attributes or the degree of imitation. Bloch et al. (1993) explore genuine and counterfeit product choice through the test of three types of products: genuine, private label and counterfeit. Product was defined through two characteristics: brand and price level. However, since they do not independently manipulate these factors, they cannot draw any conclusion about the independent or relative effects of these variables. Consequently, they suggest manipulations through conjoint analysis as a path of future research. Harvey and Walls (2003) attempt to model purchase likelihood of a fictitious counterfeit through the manipulation of genuine price and expected penalty cost (penalty magnitude and probability of penalty) associated to the counterfeit. However, as they mostly address price and penalty elasticities differences in behavior between respondents from Las Vegas and Hong-Kong, no conclusion of the relative effect of price can be drawn. Yoo and Lee (2005) manipulate price levels of both genuine and counterfeits. They state that 
"when price information is provided, preference for genuine diminishes, resulting in no significant difference from the preference of counterfeits. In addition, the hypothesis that consumers of counterfeits will show stronger intention to buy genuine items than will nonconsumers of counterfeits was not supported with price information given". Le Roux et al. (2016a,b) manipulate brand name, product appearance, price and place of purchase. Their results show a dominant pattern of choice among respondents based on Brand name over Price and Place of purchase. Differences observed between brands are explained by brand typicality.

Cultural and social context involves accounting for cultural and ethnic specificities, or comparisons between consumers from culturally or geographically distant contexts (Chapa et al., 2006; Cheung and Prendergast, 2006; Penz and Stöttinger, 2008; Veloutsou and Bian, 2008; Kwong et al., 2009; Phau and Teah, 2009).

Purchase situation relates to characteristics such as place of purchase, presence of genuine brand and expected penalty associated with purchasing counterfeits. According to Eisend and Schucher-Güler (2006), purchase situation has been largely neglected. Little research includes or manipulates different purchase settings. Bloch et al. (1993) explored two purchase settings: a commercial center and a flea market. They assumed that consumers surveyed at the flea market would be more likely to choose a counterfeit than would those contacted at the shopping mall. However, identical choice patterns were observed in both locations. D'Astous and Gargouri (2001) explored the effect of the store image on brand imitation evaluation, but they did not compare different purchase settings.

Results of the research on the determinants of counterfeit purchase are mixed, especially regarding demographics factors (Bloch et al. 1993, Lee and Yoo, 2009) as well as psychological variables (Ang et al., 2001; Cheung and Prendergast, 2006; Phau and Teah, 2009). In addition, as Lee and Yoo (2009) state, "many studies have relied on nonexperimental data" (p. 32) and few research addressed the relative importance of the various determinants. Our research will confront consumers with different types of product: genuine and counterfeit, and, in order to assess the combined effect of various determinants on preferences and purchase intentions of counterfeit, it will manipulate several variables. Since our research focuses on product category, we will select the determinants that are most related to a product, i.e. product characteristics and purchase situation. Among these two kinds of antecedents, we retain price and place of purchase, because they correspond to the cues that define a non-deceptive counterfeit in the marketing literature (Bloch et al., 1993; Gentry et al., 2001, 2006). 


\section{Counterfeits consumers' motivations profiles}

Most research consider consumers as a homogeneous population that would either purchase or not fake products. Consumers are conceived as either buyers or non-buyers of counterfeits, whatever the product category, the product attributes or the purchase situation are. Moreover, research focuses on the attitudes and behaviors of counterfeits' consumers and ignores non-users (Davcik et al., 2018).

Few studies attempt to define a plurality of consumers' profiles based on different motivations or characteristics. Tom et al. (1998) propose a typology of buyers and non-buyers of counterfeits based on two dimensions: consumer's perception of a high or low product parity between the genuine and the counterfeit product, and consumer's preference for the counterfeit or for the legitimate item. These dimensions yield a four-cell typology. A sly shopper perceives the genuine and the counterfeit products as equivalent and prefers the copy. An economically concerned shopper will prefer the counterfeit although he perceives a significant difference between the original and the fake. Price is the major driver despite the difference in quality. An ethical shopper will prefer the genuine product, although he/she perceives the original and the copy as equivalent. Price difference or product parity between both items on quality cannot justify the purchase of a fake. A risk adverse shopper perceives a significant difference between the original and the copy. The attractive price of the copy does not justify the risk of such a purchase. Although this research envisions different consumer segments depending on their evaluation of genuine and counterfeit products, it is limited to two dimensions.

Recently, Le Roux et al. (2015) propose a typology of consumers based on their motivations to buy counterfeits or not. It identifies five consumer profiles using Viot et al. (2014) 13 motivational dimensions: societal determinants (macroeconomic risk, economic risk for the company, risk of brand equity), individual deterrents (social, psychological, legal and physical risks, doubt about origin of product), individual motivations (fun dimension of counterfeits, revenge on large corporations, exorbitant price of originals, bargain price of counterfeits, low perceived quality difference between genuine and counterfeits).

Two profiles are attracted by counterfeits with differing motivations: Activists and Cynics. Activists exhibit positive attitudes and purchase intentions toward counterfeiting and counterfeits. Their motivations rely on a strong feeling of revenge against big corporations and a rejection of the negative economic consequences of counterfeiting for society, companies and brands. For them, counterfeits are attractive alternatives to genuine ones in terms of price and the "fun" dimension of the purchase, although they are fully conscious of 
the lower quality of the copies and of the legal consequences of such a behavior. Cynics exhibit unfavorable attitudes toward counterfeiting and counterfeits, but a high possession and a purchase intention of fakes. Their motivations are twofold. Like Activists, they express a feeling of revenge on big corporations, are attracted by the bargain price of counterfeits and the ludic dimension of the purchase, and perceive few differences in quality between genuine items and copies. Still, they are sensitive to social risk and brand equity risk. Two other profiles reject counterfeiting and counterfeits in terms of attitudes and purchase intentions, again for differing motivations. They are called Rationally reluctant and Emotionally resistant consumers. The former refuse to buy counterfeits for rational motivations: price and quality. They perceive a significant difference in quality between genuine items and copies that justifies price differences between the original and the counterfeits. In addition, they exhibit a mistrust of the origin of the counterfeit and reject the "fun" or "revenge on big corporations" justifications of buying fakes. This profile is similar to Tom et al. (1998) ethical shopper. The latter are defiant for more emotional reasons. They reject counterfeits because of individual risks (social, psychological, legal and physical risk) as well as more collective risks (societal risk, risk for company and for brand equity). Defiance toward counterfeits is more tied to the origin of the fake than to price or quality. This profile can be related to Tom et al. (1998) risk adverse shopper. A fifth profile corresponds to Opportunists, who exhibit unfavorable attitudes toward counterfeiting and counterfeits, and neutral motivations in terms of productrelated attributes (price and quality), revenge on big corporations or the fun of the purchase. They perceive a low risk in counterfeiting and are ready to buy fakes occasionally, as shown by their significant purchase intentions. Regarding motivations, this profile is close to Tom et al. (1998) sly shopper.

Our research will rely on Le Roux et al. (2015) typology of consumers' profiles which allows the integration of buyers and non-buyers of counterfeits and accounting for individual characteristics through consumers' motivations.

\section{Research objectives and hypotheses}

The purpose of this research is to explore the impact of product category on consumers' choice criteria hierarchy and purchase intentions in reaction to manipulation of product attributes and purchase situation in an experimental design. We hypothesize a moderating effect of product category on the hierarchy of choice criteria. Price and place of purchase relative importance, as well as modality preference within these attributes, will differ for a more expensive and risky product category compared to a less expensive and risky 
one. Regarding purchase intentions, we expect interactions between determinants of consumer behavior toward copies and genuine items: product category, price and place of purchase.

In addition, since regarding counterfeiting consumers cannot be considered as a homogenous population, we will investigate if product category, product type, price, place of purchase effects on preferences and purchase behavior differ among consumers' motivations profiles. We hypothesize a moderating effect of consumers' motivations profiles on product type, price and place of purchase. Product type, price and place of purchase relative importance as well as modality preference will differ among consumers' profiles. We expect some consumers' profile to be more sensitive to product type, while others will be more sensitive to price. Regarding purchase intentions, we expect interactions between product category, product type, price and place of purchase.

\section{Methodology}

The research involves an experimental survey that comprises a trade-off model. In addition, the questionnaire includes a psychometric scale measuring consumers' motivations to purchase or not counterfeits, a manipulation check on perceived risk of the selected product categories, and socio-demographics.

The research encompasses two product categories: a low risk and less expensive product, an Eastpak backpack, a higher risk and more expensive product with a technological dimension, a Canon digital camera. In the questionnaire, perceived risk associated with each product category is measured on a single Likert item ("For me the purchase of a digital camera / a backpack is a risky one") using a five-point scale ( $1=$ Not at all risky, $5=$ Very risky). A manipulation check through a $t$ test confirms a significant difference in perceived risk for the two selected product categories $(t=13.039, d f=169$, p-value $<0.001)$.

The main part of the study is an experiment where respondents are presented a set of ten stimuli built with an orthogonal design of main effects: Product type (explicit mention: genuine products $v s$ counterfeits), Price (high: public price observed on market $v s$ low: $33 \%$ of public price), Place of purchase (regular shop, Internet, market). The orthogonal design ensures a zero correlation between the main effects.

The stimuli used (see Appendix) involve a pictorial representation of the product specifying the place of purchase, the price and the product type, along with a scenario presenting the purchase situation: "While on a trip abroad, in a shop / on Internet / at a market, you are proposed a Canon digital camera lan Eastpak backpack for a price of low / high. It's a genuine product / a counterfeit" (italics for variations). The scenario is used to 
improve the ecological validity of the survey. It is unlikely to encounter counterfeits in a regular shop in western countries, as no distributor would accept risking its brand image through counterfeit selling. The mention of a foreign setting attempts to account for this aspect.

The data is collected on a convenience sample of 170 respondents (male $=31 \%$, female $=69 \%$, age in years: mean $=22.76, \mathrm{SD}=1.81)$. Fieldwork was conducted among students in a French university from October 2013 to February 2014. Each respondent has to rank without ties all ten stimuli in each product category from the most preferred to the least one. In addition, for each stimulus, a purchase intention is collected on a four-point scale (Would you buy this product?: 1 = certainly not, 4 = certainly).

The impact of product category, product characteristics and purchase situation on consumer behavior is explored through a conjoint analysis methodology using the TRANSREG ${ }^{1}$ procedure in a non-metric way: rankings are allowed to be transformed in an optimal manner preserving only monotonicity. The purpose of the conjoint analysis is to describe and model consumers' preferences (Green and Srinivasan, 1990). It allows the identification of the attributes a consumer uses to evaluate an object, the relative importance of each one, and the preferred modalities.

To cross-validate the attributes preferences expressed in rankings, we then analyze the ordinal purchase intentions of each stimulus by fitting a Generalized Linear Mixed Model (GLMM, see Agresti, 2013 for details). The GLIMMIX ${ }^{1}$ procedure is used: the independent variables for comparisons (i.e. Product category and Consumers' motivations profiles) are considered as nominal variables. The dependent variables (i.e. 4 levels of buying intention) are considered following conditional binomial distributions constrained by the order condition. A cumulative logit transformation was used. The respondents are random intercepts. This type of analysis has a better support from probability theory and allows statistical tests of complex hypotheses. The research model is as follows: the buying intentions are a non-linear function of the buying context (i.e. Product category, Product type, Price, and Place of purchase). The baseline models are built with three main effects: Product type, Price, and Place of purchase, adding the product category as a moderator. The treatment of individuals as random factors allows eliminating spurious correlations induced by the fact that each respondent has expressed his intention for each stimulus and that, consequently, these scores cannot be considered independent and identically distributed. The estimation

\footnotetext{
${ }^{1}$ SAS Institute Inc. (2017). SAS/STAT® 14.3 User’s Guide. Cary, NC:SAS Institute Inc.
} 
technique used here is the Gauss quadrature. A systematic check with a Laplace approximation eliminated the risk of a local optimum of the likelihood function.

The use of two measures, ranking of products and buying intentions, is made for the sake of robustness of the results. Both measures have their drawbacks: the forced distribution of the rankings, without ties, can sometimes introduce artificial differences between buying contexts. At the opposite, the ties induced in the buying intention could mask different degrees of rejection of a product or a context. Crossing the two measurement processes and obtaining consistent results is a way to overcome these limitations.

Finally, Consumers' motivations profiles are introduced using cluster membership from Le Roux et al. (2015) based on Viot et al. (2014) psychometric scale measuring consumers' motivations to purchase or not counterfeits. In the conjoint analysis, a trade-off is run for each consumers' motivations profile. In GLMM analysis, the cluster membership from Le Roux et al. (2015) is added as a categorical moderator variable to highlight differences in the decision-making determinants. The research model becomes as follows: the buying intentions are a non-linear function of the buying context (i.e. Product category, Product type, Price, and Place of purchase) and Consumers' motivations profiles regarding counterfeiting. The generating processes of the experimental design, on one hand, and the grouping of respondents based on their motivations, on the other hand, are totally independent. Thus, no form of collinearity or feedback is to be feared.

\section{Results}

First, we investigate how consumers react to the manipulation of product attributes and purchase setting in the selected product categories by comparing both rankings and purchase intentions. Then, consumers' profiles are introduced in the analysis in order to assess their influence on stimuli choice and purchase behavior.

\section{Investigating Product category effect on stimuli ranking through conjoint}

\section{analysis}

The conjoint analysis allows the estimation of the relative importance of each of the manipulated factors for the selected product categories. For both product categories, a logical hierarchy in variable importance is observed: Product type is the dominant choice criterion (relative importance: digital camera $=43.16 \%$, backpack $=42.98 \%$ ), ahead of Price (respectively $31.95 \%$ and $37.23 \%$ ) and Place of purchase (respectively $24.89 \%$ and $19.79 \%$ ). However, a product category effect is suggested by a slight difference between the product 
classes tested: while the hierarchy of importance is clear for the backpack, Price and Place of purchase are closer in importance for the digital camera.

For both product categories, respondents exhibit rational preferences: they prefer a genuine to a fake, a low price to a high one, a regular shop to Internet and to the market. Again, a product category effect is suggested through a slight difference regarding the Place of purchase: For the backpack, Internet $($ Utility $=-0.40)$ and the market $($ Utility $=-0.65)$ are equally rejected. However, for the digital camera, while the shop is overwhelmingly preferred $($ Utility $=1.03)$, Internet becomes a slightly acceptable modality $($ Utility $=0.07)$, and the market is strongly rejected (Utility $=-1.10)$.

In conclusion, conjoint analysis suggests a product category effect on the ranking of stimuli. However, this type of analysis does not provide any indicator of the significance of the product category effect. Therefore, a Generalized Linear Mixed Model is used in order to estimate the moderating effect of the product category on purchase intentions.

\section{Investigating Product category effect on purchase intentions through a}

\section{Generalized Linear Mixed Model}

The final model has an AICC (6250.21) drastically smaller than the intercept-only model (8339.79) for only eleven (11) additional parameters, showing a very good fit. The random intercept by respondent $\times$ category is significant $(\operatorname{var}=1.137$, std err $=0.189)$, which validates the choice of a mixed model. The type III tests are given in table 1.

\section{Insert Table 1 here}

All main effects are significant and the estimators for the attributes are those expected: for the backpack, which is the reference category. A genuine product exhibits higher purchase intentions than a counterfeit $(t=13.04)$, a low price than a high price $(t=18.94)$. Regarding Place, a purchase in a store is strictly preferred to a purchase on the Internet $(t=3.24)$, which in turn is strictly preferred over a market $(t=3.75)$. These results parallel those of the conjoint analysis and confirm that respondents used all three manipulated attributes to rank products and to state their purchase intentions. No three-way interaction was found significant. The effect of the product category will be investigated through the analysis of the significant twoway interactions.

A moderating effect of the product category can be observed for Price and Place of purchase. A significant Product category x Price interaction indicates that, compared to the 
reference category (backpack), a low-priced camera is less likely to be bought $(t=2.94)$, which corresponds to the smaller importance of Price seen in the conjoint analysis. A significant Product category x Place of purchase interaction shows that the intention to buy a camera on the Internet is, relative to the backpack, closer to the physical shop $(t=1.68, \mathrm{p}$ value $>0.05)$ and farther from the market $(t=4.07)$.

In addition, a significant Product type and Place interaction means that a counterfeit is more likely to be bought at a market $(t=3.85)$ than predicted by the main effects only. A significant Product type and Price interaction shows that, for a counterfeit, a low price is not sufficient to trigger the purchase $(t=2.40)$. A significant Place of purchase and Price interaction indicates that a low price is specially appreciated in a regular shop $(t=2.83)$.

\section{Investigating Consumers' motivations profiles effect on stimuli ranking through conjoint analysis}

The conjoint analysis was re-run on each of the five consumer clusters, for each product category tested (see Table 2). This analysis allows accounting for the impact of consumers' motivations profiles on rankings of stimuli. Results suggest a consumer profiles effect. In the backpack product category, three different hierarchies are observed. On one side, consumer profiles opposed to counterfeiting (i.e. Rationally reluctant and Emotionally resistant consumers) express a choice overwhelmingly based on Product type. On the other side, Activists exhibit a choice based mainly on Price. Cynics and Opportunists are inbetween with a choice based on Product type and Price, with similar importance for each variable.

\section{Insert Table 2 here}

However, in the digital camera product category, results are homogeneous across consumer profiles. All clusters exhibit the same clear hierarchy regarding attributes importance: Product type is the dominant choice criterion, ahead of Price and Place of purchase. Therefore, a product category effect can be observed, along with the impact of consumers' motivations profiles.

\section{Investigating Consumers' motivations profiles effect on purchase intentions through a Generalized Linear Mixed Model}

The consumers' profiles have been introduced into the model. Overall, the direct and indirect effects observed in the previous GLMM remain significant. Introducing the cluster 
membership as a moderator enhances the fit. The AICC of the baseline model (6250.21) becomes 6187.41 for a model including the cluster and two interactions: Cluster $\times$ Product type and Cluster $\times$ Price. For 9 additional parameters to estimate, this is significant at the $0.1 \%$ level. The moderating effect of cluster membership is significant for Product type $(\mathrm{F}=$ 3.12 , num $d f=4$, $\mathrm{p}$-value $=0.0144)$ and for Price $(\mathrm{F}=9.76$, num $d f=4$, $\mathrm{p}$-value $<0.001)$. The estimates are shown in table 3.

\section{Insert Table 3 here}

A series of contrasts summarizes our main findings. Regarding Product type, the total marginal effect of cluster membership clearly opposes Activists and Cynics vs. Rationally reluctant and Emotionally resistant consumers $(t=3.03)$, the former being less opposed to buying fakes, and Opportunists being in between. All profiles prefer to buy a genuine product, but the Activists are more prone than all other clusters to buy a counterfeit $(t=2.10)$, once again followed by Cynics and Opportunists $(t=3.29)$.

Regarding Price, at a high price, there is no real difference between profiles as the most frequent answer is "certainly not", but for a low price, Cynics, Activists and, to a lesser extent, Opportunists will buy more often, regardless of the other attributes of the trade-off $(t=$ 5.34).

\section{Discussion}

This research explores the impact of product category and consumers' motivations profiles on consumers' choice criteria and behaviors regarding counterfeiting through the manipulation of product attributes and purchase setting (i.e. Product type, Price and Place of purchase).

\section{Importance of manipulating product characteristics and purchase situation}

This research highlights a dominant pattern in consumer behavior regarding counterfeiting: Product type, Price and Place of purchase. Literature identifies the same decision criteria (Bloch et al., 1993; Gentry et al., 2001, 2006), but it emphasizes the dominant role of price in consumer decision making. Our results highlight the importance of product type, before price. Therefore, price cannot be considered as the dominant choice criterion contrary to what literature suggests. In addition, regarding price effects, literature suggests that the low price of counterfeits attracts consumers (Harvey and Walls 2003; Gentry et al., 2006; Staake and Fleisch, 2008; Lee and Yoo, 2009). However, according to our 
results, if a low price attracts consumers especially in the case of a regular shop, a low price is not sufficient to trigger a counterfeit purchase. Therefore, price alone cannot determine a counterfeit purchase. It is the interaction of Price, Place of purchase or Product type that explains such a behavior.

Furthermore, contrary to Bloch et al. (1993) results, our research shows that Place of purchase is a significant choice criteria for consumers regarding counterfeits. A consumer is more likely to buy a counterfeit at a market than in a regular shop or on the Internet.

In conclusion, through product characteristics and purchase setting manipulations, our research shows that various criteria, in addition to price, matter for consumers, in purchasing or not counterfeit or genuine.

\section{Product category matters}

Relative importance of Place of purchase and Price varies according to Product category. Place of purchase preferences are different according to Product category: Internet is an acceptable Place of purchase for a digital camera, while it is not true for a backpack. In addition, depending upon Product category, purchase intentions in different Places of purchase vary. Therefore, as Product category influences Place of purchase perception and role, it needs to be accounted for. As noticed by Eisend and Schucher-Güler (2006), purchase situation has been largely neglected in literature. Our results show that it is an important dimension of consumer behavior. Bloch et al. (1993) and D'Astous and Gargouri (2001) highlight differences in consumers' reactions to purchase setting. However, they did not provide any evidence of the type of effect or influence of such a variable on consumer behavior.

Product category influences Price importance: for some products, such as a camera, a low price is less attractive than for a more mundane product category (i.e. backpack). Therefore, Price importance in a purchase cannot be considered without accounting for Product category. Again, our results challenge the assumption in literature that the price advantage of a counterfeit attracts consumer purchase. This price advantage may be more or less attractive for consumers, depending upon product category.

However, Product category does not interact with Product Type. It suggests that no product category is safe from counterfeiting. There is no product category in which a consumer will never consider, or will always consider, buying a counterfeit. The decision of buying a fake is a combination of Product category, Price or Place of purchase. 


\section{Consumers' Motivations Profiles matter}

Consumers' profiles have been scarcely studied in literature. So far, only typologies of consumer profiles have been proposed (Tom et al. 1998; Le Roux et al., 2015) but have not been related to consumers' preferences and purchase intentions. Our research shows a moderating effect of Consumers' profiles on buying behavior. Some profiles are more receptive to counterfeits: Activists and Cynics are less opposed to counterfeits than Rational reluctant and Emotionally resistant consumers. Moreover, some profiles are more attracted by a low price: Opportunists, Activists and Cynics express a higher preference for a low price. Face with counterfeiting and price, all consumers do not react in the same way. Therefore, consumers' motivations profiles need to be accounted for when considering consumer behavior regarding counterfeiting. In the literature, the influence of psychological variables, such as motivations, on consumer behavior has been studied in isolation (i.e.: influence of perceived risk on attitude and purchase intention of counterfeits), resulting in mixed conclusions. Our research accounts for the influence of a combination of motivations through consumers' profiles. Such a perspective allows research to account for the influence of motivations through consumers' profiles. For example, perceived risk is a major determinant for Emotionally resistant consumers, while it is not relevant for Activists or Opportunists.

In addition, Consumers' profiles exhibit different choice criteria hierarchies depending upon the product category considered. For the backpack, Activists main choice criterion is Price, Opportunists and Cynics equally weight Price and Product type, Rationally reluctant and Emotionally resistant consumers' choice is based on Product type. However, when considering the digital camera, all profiles have the same main choice criterion: i.e. Product type. A same consumers' profile may change its choice criteria depending upon the product category considered. For an Activist, a counterfeit may be acceptable in a low perceived risk (i.e. functional, financial, physical, social, psychological risk, Jacoby and Kaplan, 1972) product category, while it will not be accepted in a high perceived risk product category. Therefore, it seems that both moderating variables identified in this research interact: Product category and Consumers' motivations profiles.

From an academic standpoint, this research confirms the role of product attributes, such as Price, and purchase setting such as Place of purchase, as important determinants of consumers' purchase behavior of counterfeits. In addition, our results bring new insights regarding the hierarchy of choice criteria, with Product type as the major choice criterion ahead of Price and Place of purchase. This result contradicts existing literature that pinpoints price as the major determinant of a counterfeit purchase. Moreover, product category matters 
in understanding consumers' reactions to counterfeits and genuine. This research highlights the difference in relative importance of choice criteria (i.e. Place of purchase and Price) between the two product categories tested. In addition, Product category interacts with Price and Place of purchase. Again, these findings challenge the existing literature that emphasizes the importance of price. Price effects are to be considered in relation to other variables, i.e. Product category, Place of purchase or Product type.

Finally, our research brings new insights in introducing the role of Consumers' profiles in relation to Price, Place of purchase, Product type and Product category. Consumers are not a homogeneous population face to counterfeiting. Some profiles are more receptive than others to counterfeiting and exhibit different hierarchies of purchase criteria. In addition, some profiles may change their hierarchies depending on Product category. Contrasting consumers' profiles allows better understanding of the role of the different determinants studied and their inter-relatedness.

From a managerial standpoint, this research emphasizes the need to adopt a global and a targeted approach when it comes to counterfeiting.

A global approach is vital due to the interactions between Product category, Price and Purchase situation. Situation-related variables are crucial in fighting counterfeiting, as the place of purchase is a major cue to categorize items, i.e. genuine or fake. It is therefore of the utmost importance to warrant retailers cooperation in fighting counterfeiting. In addition, price setting of genuine must be done in considering place of purchase and product category.

Consumers diversity regarding motivations and behaviors faced with counterfeits pleads for a diversified and targeted approach to counterfeit warnings. Targeted communication campaigns, designed to make the different profiles perceive the drawbacks and dangers of counterfeiting, may help to deter them from buying fakes. In addition, the interactions observed between Consumers' profiles and Price or Product type show that three profiles are more easily attracted by low price or counterfeits. These segments constitute a major threat for genuine manufacturers and priority targets for communication and legal actions.

\section{Limitations and future research}

This research presents several limitations. It has been conducted on a convenience sample, considering only two product categories, and manipulating only one product attribute, price on two modalities, and one purchase setting, place of purchase, on three modalities. 
Results cannot therefore be generalized to other populations, product categories, product attributes or settings. Further research could include a more representative sample of the population of consumers, additional product categories and attributes. Moreover, Product type comprised only two modalities, genuine or counterfeits without considering varying degrees of similarity. 


\section{References}

Agresti, A. (2013), Categorical Data Analysis, New York, NY, Wiley-Blackwell. Albers-Miller N. (1999), "Consumer misbehavior: why people buy illicit goods", Journal of Consumer Marketing, Vol. 16 No. 3, pp. 273-287.

Ang, S. W., Cheng, P. S., Lim, E. A. C., and Tambyah, S. K. (2001), "Spot the difference: consumer responses toward counterfeits", Journal of Consumer Marketing, Vol. 18 No3, pp.218-235.

Baghi, I., Gabrielli, V. and Grappi, S. (2016), "Consumerse awareness of luxury brand counterfeits and their subsequent responses: when a threat becomes an opportunity for the genuine brand", Journal of Product \& Brand Management, Vol. 25 No. 5, pp. 452-464. Bamossy, G. and Scammon, L. D. (1985), "Product counterfeit: consumers and manufacturer beware", in Hirschmann E. C. \& Holbrook M. B. (eds) Advances in Consumer Research, Vol. 12, Association for Consumer Research, Provo UT, pp. 334-339.

Bian, X. and Moutinho, L. (2009), "An investigation of determinant of purchase consideration", Journal of Business Research; Vol. 62 pp. 368-378.

Bian X. and Moutinho L. (2011): "Counterfeit and branded products: effects of counterfeit ownership", Journal of Product and Brand Management, Vol. 20 No. 5, pp. 379-393.

Bian, X., Wang, K.., Smith, A., Yannopoulou, N. (2016), " New insights into unethical counterfeit consumption", Journal of Business Research, Vol. 69 N¹0, pp. 4249-4258. Bloch, P. H., Bush, R. F. and Campbell, L. (1993), "Consumer 'Accomplices' in product counterfeiting", Journal of Consumer Marketing, Vol. 10 No 4, pp. 27-36.

Cesareo, L. (2016), Counterfeiting and Piracy, A Comprehensive Literature Review, Springer, New York.

Cesareo, L., and Stöttinger, B. (2015), "United we stand, divided we fall: How firms can engage consumers in their fight against counterfeits", Business Horizons, Vol. 58, pp. 527537.

Chapa, S., Minor, M.S. and Maldonado, C. (2006), "Product Category and Origin Effects on Consumer Responses to Counterfeits: Comparing Mexico and the U.S.", Journal of International Consumer Marketing, Vol. 18 No. 4, pp. 79-99.

Chaudhry, P., Peters, J. R., Cordell, V., and Zimmerman A. (2005), "Modelling anticounterfeiting strategies in response to protecting intellectual property rights in a global environment", The Marketing Review, Vol. 5, No. 1, pp. 59-72. 
Cheung, W. L. and Prendergast, G. (2006), "Exploring the materialism and conformity motivations of Chinese pirated product buyers", Journal of International Consumer Marketing, Vol. 18 No. 3, 17-31.

Commuri, S. (2009), the impact of counterfeiting on genuine-item consumer's brand relationship, Journal of Marketing, Vol. 73, May 2009, pp. 86-98.

Cordell, V. V., Wontgdata, N., and Kieschnick R. L. (1996), "Counterfeit purchase intentions: role of lawfulness attitudes and product traits determinants", Journal of Business Research, Vol. 35 No. 41, pp;41-53.

D’Astous, A. and Gargouri, E. (2001), "Consumer evaluations of brand imitations", European Journal of Marketing, Vol. 35 No; 1², pp.153-167.

Davcik, N.S, Sharma, P., Chan, R. and Roy, R. (2018), "Deliberate Lookalikes: Pas, Present and Future Research", Call for Paper, Special Issue, Journal of Product and Brand Management.

De Matos, C.A., Ituassu, C.T. and Rossi, C.A.V. (2007), "Consumer attitudes toward counterfeits: a review and extension", Journal of Consumer Marketing, Vol. 24 No. 1, pp. 3647.

Eisend, M. (2017), "Morality Effects and Consumer Responses to Counterfeit and Pirated Products: A Meta-analysis", Journal of Business Ethics, Vol. 139 №4, doi 10.1007/s10551016-3406-1.

Eisend, M., Schucher-Güler, P. (2006), "Explaining Counterfeit Purchase: A Review and Preview", Academy of Marketing Science Review, Vol. n¹2, pp. 1-22.

http://www.amsreview.org/articles/eisend12-2006.pdf

Geiger-Oneto, S., Gelb, B.D., Walker, D. and Hess, J.D. (2013): "“Buying status” by choosing or rejecting luxury brands and their counterfeits", Journal of the Academy of Marketing Science, Vol. 41 No. 3, pp. 357-372.

Gentry, J. W., Putrevu, S., Shulz, C. and Commuri, S. (2001), "How now Ralph Lauren? The separation of brand and product in a counterfeit culture", in M. C. Gilly et J. Meyers-Levy (eds.), Advances in Consumer Research, Vol. 28, Association for Consumer Research, Valdosta, GA, pp. 258-265.

Gentry, J. W., Putrevu, S. and Shulz, C. (2006), "The effects of counterfeiting on consumer search", Journal of Consumer Behavior, Vol. 5 No3, p. 245-256.

Gistri, G., Romani, S., Pace, S., Gabrielli, V. and Grappi, S. (2009), "Consumption Practices of counterfeit luxury goods in the Italian context", Journal of Brand Management, Vol. 16 $\mathrm{N}^{\circ} 5 / 6$, pp. 364-374. 
Green, P. E. and V. Srinivasan (1990). "Conjoint Analysis in Marketing: New Developments with Implications for Research and Practice." Journal of Marketing, Vol. 54 №4, pp. 3-19 Hamelin, N., Nwankwo, S. and El Hadouchi, R. (2013), "'Faking brands': Consumer responses to counterfeiting", Journal of Consumer Behaviour, Vol. 12 No. 3, pp. 159-170. Harvey, P. J. and Walls, W. D. (2003), "Laboratory markets in counterfeit goods : Hong Kong versus Las Vegas", Applied economics Letters, Vol. 10, pp. 883-887.

Hieke, S. (2010), "Effects of counterfeits on the image of luxury brands: An empirical study from the consumer perspective", Journal of Brand Management, Vol. 18, n², pp. 159-173. Jacoby, J. and Kaplan, L. B. (1972), "The Components of Perceived Risk", in SV Proceedings of the Third Annual Conference of the Association for Consumer Research, eds. M. Venkatesan, Chicago, IL : Association for Consumer Research, pp 382-393. Kwong, K. K., Yu, W. Y. P., Leung, J. W. K. and Kan, W. (2009) : "Attitude toward counterfeit and ethnic groups; comparing Chinese versus Western Consumers", Journal of Euromarketing, Vol. 18 No. 3, p. 157-169.

Le Roux, A., Thébault, M. and Bobrie, F. (2015), "Les consommateurs de contrefaçon : le prix n'est pas la seule motivation", Recherches en Sciences de Gestion, No. 107, p. 25-41. Le Roux, A., Bobrie, F. and Thébault, M. (2016a): "A typology of brand counterfeiting and imitation based on a semiotic approach", Journal of Business Research, Vol. 69 n 1, pp. 349356.

Le Roux, A., Bobrie, F., Roy, Y. and Thébault M. (2016b), "Brand typicality impact on brand imitations evaluation and categorization", Journal of Product and Brand Management, Vol. 25 No. 6, pp. 600-612.

Lee, S. H. and Yoo, B (2009), "A Review of the Determinants of Counterfeiting and Piracy and the Proposition for Future Research", The Korean Journal of Policy Studies, Vol. 24, No. 1, pp. 1-38.

McCarthy, J. T. (2004), McCarthy's Desk Encyclopedia of Intellectual Property, Third Edition. Washington, DC: Bureau of National Affairs.

Moores, T. and Dhillon, G.. (2000), "Software Piracy: A View from Hong Kong.", Communications of the ACM, Vol. 43 No. 12, pp. 88-93.

OECD/EUIPO (2016), Trade in Counterfeit and Pirated Goods : Mapping the Economic Impact, Éditions OCDE, Paris, http://dx.doi.org/10.1787/9789264252653-en.

Penz, E. and Stöttinger, B. (2005), Forget the "Real" thing-Take the copy! An explanatory model for the volitional purchase of counterfeit products, in Advances in Consumer Research, Vol. 32, pp. 568-575. 
Penz, E. and Stöttinger, B. (2008), "Corporate image and product similarity - Assessing major demand drivers for counterfeits in a multi-country study ", Psychology \& Marketing, Vol. 25 No. 4, pp. 352-381.

Phau, I and Teah M. (2009), "Devil wears (counterfeit) Prada: A study of antecedents and outcomes of attitudes towards counterfeits of luxury brands", Journal of Consumer Marketing, Vol. $26 \mathrm{~N}^{\circ} 1$ pp. 15-27.

Prendergast G., Chuen L. H. and Phau I. (2002), "Understanding consumer demand for nondeceptive pirated brands", Marketing Intelligence \& Planning, Vol. 20 No. 7, pp. 405-416. Romani, S., Gistri, G. and Pace, S. (2012), "When counterfeits raise the appeal of luxury brands", Marketing Letters, Vol. 23 No. 3, pp. 807-824.

Schlegelmilch, B. B. and Stöttinger, B. (1999), "Der Kauf gefälschter Markenprodukte: Die Lust auf das Verbotene." Marketing ZFP, Vol. 22 No. 3, pp. 196-208.

Staake, T., and Fleisch, E. (2008), Countering counterfeit trade: Illicit market insights, bestpractice strategies, and management toolbox, Springer, Berlin.

Staake, T, Thiesse, F. and Fleisch, E. (2009), "The emergence of counterfeit trade: a literature review", European Journal of Marketing, Vol. 43 No. 3/4, pp. 320,349

Staake, T, Thiesse, F. and Fleisch, E. (2012), "Business strategies in the counterfeit market", Journal of Business Research, Vol. 65 N5, pp. 658-665.

Tom, G., Garibaldi, B. Zeng, Y., and Pilcher, J. (1998), "Consumer demands for counterfeit goods", Psychology \& Marketing, Vol. 15 No. 5, pp. 405-421.

VDMA (2018), "Germany: Product piracy continues to cause great damage in the mechanical engineering industry", http://www.contrefacon-riposte.info/indicateurs/5709-germanyproduct-piracy-continues-to-cause-great-damage-in-the-mechanical-engineering-industry. Van Buuren, S. (2007), "Multiple Imputation of Discrete and Continuous Data by Fully Conditional Specification", Statistical Methods in Medical Research, Vol. 16, pp. 219-242. Veloutsou, C. and Bian, X. (2008), "A cross-national examination of consumer perceived risk in the context of non-deceptive counterfeit brands", Journal of Consumer Behavior, Vol. 7 No. 1, pp. 3-20.

Viot, C., Le Roux, A. and Kremer, F. (2014), " Attitude towards the purchase of counterfeits: Antecedents and effect on intention to purchase", Recherches et Applications en Marketing, Vol. 29, n³ p. 3-33.

Wilcox, K., Kim, H. M. and Sen, S. (2009), "Why Do Consumers Buy Counterfeit Luxury Brands?", Journal of Marketing Research, Vol. 46 No. 2, pp. 247-259. 
Yoo, B. and Lee, S. H. (2005), "Do counterfeits promote genuine products?", working paper: http://www.hofstra.edu/pdf/BIZ mlc workingpaper7.pdf.

Zaichkowsky, J.L. (2006), The psychology behind trademark infringement and counterfeiting, Lawrence Erlbaum Associates, Psychology Press, Mahwah, N.J

Table 1: Results of Type III tests for the baseline GLMM

\begin{tabular}{lrrr}
\hline & Type III Tests of Fixed Effects \\
Effect & 1 & 3047 & $852.21<.0001$ \\
Product type & 1 & 3047 & $796.77<.0001$ \\
Price & 2 & 3047 & $83.38<.0001$ \\
Place & 1 & 3047 & 5.770 .0164 \\
Product type*Price & 1 & 3047 & $39.19<.0001$ \\
Product type*Place & 1 & 3047 & 8.040 .0046 \\
Price*Place & 1 & 338 & 6.410 .0118 \\
Product Category & 1 & 3047 & 8.660 .0033 \\
Product Category *Price & 2 & 3047 & 8.920 .0001 \\
Product Category *Place & &
\end{tabular}


Table 2: Results of Conjoint analysis by consumer profile

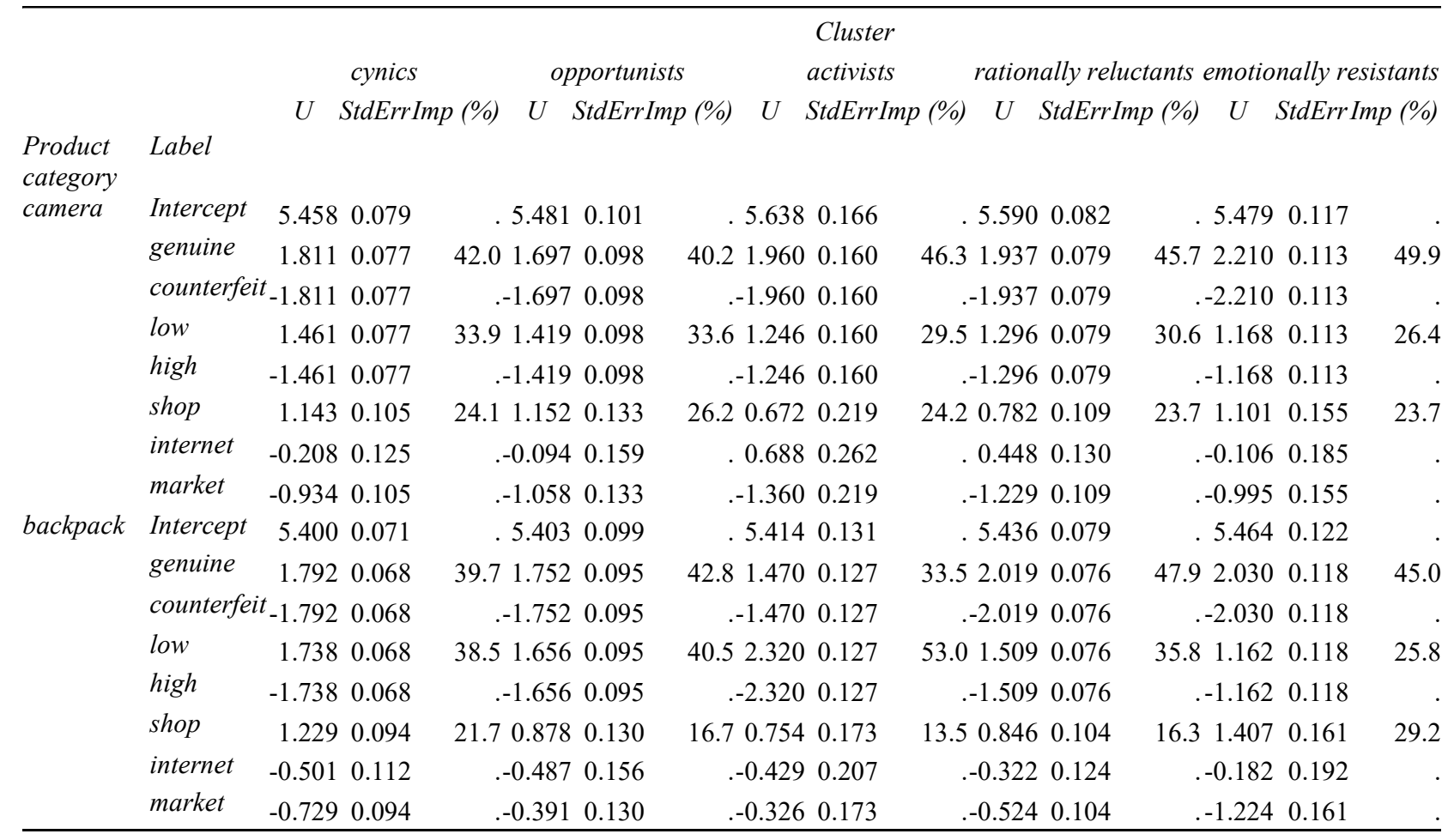


Table 3: Results of Generalized Linear Mixed Model including consumers

profiles

\begin{tabular}{|c|c|c|c|c|c|c|c|c|c|}
\hline & & & & utions for $F$ & Fixed Effe & cts & & & \\
\hline & Purchase & Product & & Product & & & & tandard & $\operatorname{Pr}>$ \\
\hline Effect & intention & category & Price & type & Place & Cluster & Estimate & Error $D F t$ & Value \\
\hline Intercept & certainly not & & & & & & 0.2497 & 0.3097334 & 0.810 .4207 \\
\hline Intercept & probably not & & & & & & 2.3131 & $0.3135 \quad 334$ & $7.38<.0001$ \\
\hline Intercept & probably & & & & & & 4.3779 & 0.3256334 & $13.44<.0001$ \\
\hline Cluster & & & & & & cynics & -0.3080 & 0.3201334 & -0.960 .3366 \\
\hline Cluster & & & & & & opportunists & 0.3059 & 0.3418334 & 0.900 .3714 \\
\hline Cluster & & & & & & activists & 0.4335 & 0.4433334 & 0.980 .3289 \\
\hline Cluster & & & & & & rationally reluctants & -0.09399 & 0.3245334 & -0.290 .7722 \\
\hline Cluster & & & & & & emotionally resistants & 0 & . & ${ }^{\circ}$ \\
\hline Product category & & digital camera & & & & & 0.6153 & $0.2083 \quad 334$ & 2.950 .0034 \\
\hline Product category & & backpack & & & & & 0 & . & . \\
\hline Price & & & Low & & & & -2.3974 & 0.28973039 & $-8.28<.0001$ \\
\hline Price & & & High & & & & 0 & . & . \\
\hline Product type & & & & counterfeit & & & 2.4849 & 0.31593039 & $7.87<.0001$ \\
\hline Product type & & & & genuine & & & 0 & . & . $\quad$. \\
\hline Place & & & & & shop & & -1.2660 & 0.16553039 & $-7.65<.0001$ \\
\hline Place & & & & & internet & & -0.6940 & 0.18183039 & -3.820 .0001 \\
\hline Place & & & & & market & & 0 & . & . \\
\hline Product category $*$ Price & & digital camera & Low & & & & 0.4715 & 0.15383039 & 3.070 .0022 \\
\hline Product category *Price & & digital camera & High & & & & 0 & . & . \\
\hline Product category $*$ Price & & backpack & Low & & & & 0 & . & . \\
\hline Product category *Price & & backpack & High & & & & 0 & . & . \\
\hline Product category *Place & & digital camera & & & shop & & -0.4886 & 0.17173039 & -2.850 .0045 \\
\hline Product category *Place & & digital camera & & & internet & & -0.8093 & 0.20113039 & $-4.03<.0001$ \\
\hline Product category *Place & & digital camera & & & market & & 0 & . & . \\
\hline Product category *Place & & backpack & & & shop & & 0 & . & . \\
\hline Product category *Place & & backpack & & & internet & & 0 & . & . \\
\hline Product category *Place & & backpack & & & market & & 0 & . & . \\
\hline Product type*Place & & & & counterfeit & shop & & 1.1518 & 0.18243039 & $6.31<.0001$ \\
\hline Product type*Place & & & & counterfeit & internet & & 0.8741 & 0.22723039 & 3.850 .0001 \\
\hline Product type*Place & & & & counterfeit & market & & 0 & . & . \\
\hline Product type*place & & & & genuine & shop & & 0 & . & . \\
\hline Product type*Place & & & & genuine & internet & & 0 & . & . \\
\hline Product type*Place & & & & genuine & market & & 0 & . & . \\
\hline Price* Product type & & & Low & counterfeit & & & 0.4953 & 0.19453039 & 2.550 .0109 \\
\hline Price* Product type & & & Low & genuine & & & 0 & . & . \\
\hline Price* Product type & & & High & counterfeit & & & 0 & . & . \\
\hline Price* Product type & & & High & genuine & & & 0 & . & . \\
\hline Price*Place & & & Low & & shop & & -0.5364 & 0.18073039 & -2.970 .0030 \\
\hline Price*Place & & & Low & & internet & & 0 & . & . \\
\hline Price*Place & & & Low & & market & & 0 & . & . \\
\hline Price*Place & & & High & & shop & & 0 & . & . \\
\hline Price*Place & & & High & & internet & & 0 & . & . \\
\hline Price*Place & & & High & & market & & 0 & . & . \\
\hline Product type*Cluster & & & & counterfeit & & cynics & -0.1863 & 0.30223039 & -0.620 .5376 \\
\hline Product type*Cluster & & & & counterfeit & & opportunists & 0.07009 & 0.32793039 & 0.210 .8308 \\
\hline Product type*Cluster & & & & counterfeit & & activists & -1.1022 & 0.39933039 & -2.760 .0058 \\
\hline Product type*Cluster & & & & counterfeit & & rationally reluctants & -0.01771 & 0.30773039 & -0.060 .9541 \\
\hline Product type*Cluster & & & & counterfeit & & emotionally resistants & 0 & . . & . \\
\hline Product type*Cluster & & & & genuine & & cynics & 0 & . & . \\
\hline Product type*Cluster & & & & genuine & & opportunists & 0 & . & . \\
\hline Product Type*Cluster & & & & genuine & & activists & 0 & . & . \\
\hline Product type*Cluster & & & & genuine & & rationally reluctants & 0 & . & . \\
\hline Product type*Cluster & & & & genuine & & emotionally resistants & 0 & . & . \\
\hline Price*Cluster & & & Low & & & cynics & -1.1076 & 0.29353039 & -3.770 .0002 \\
\hline Price*Cluster & & & Low & & & opportunists & -1.6209 & 0.32143039 & $-5.04<.0001$ \\
\hline Price*Cluster & & & Low & & & activists & -1.0673 & 0.39663039 & -2.690 .0072 \\
\hline Price*Cluster & & & Low & & & rationally reluctants & -0.3765 & 0.29663039 & -1.270 .2045 \\
\hline Price*Cluster & & & Low & & & emotionally resistants & 0 & . & . \\
\hline Price*Cluster & & & High & & & cynics & 0 & . & . \\
\hline Price*Cluster & & & High & & & opportunists & 0 & . & . \\
\hline Price*Cluster & & & High & & & activists & 0 & . & . \\
\hline Price*Cluster & & & High & & & rationally reluctants & 0 & . & . \\
\hline Price*Cluster & & & High & & & emotionally resistants & 0 & . & . \\
\hline
\end{tabular}


Appendix: Stimuli used in the survey

\section{PRODUCT X}

"While on a trip abroad, in a shop / on Internet / to a market, you are

proposed a Canon digital camera for a price of $156 € / 469 €$. It's a genuine

product / a counterfeit"

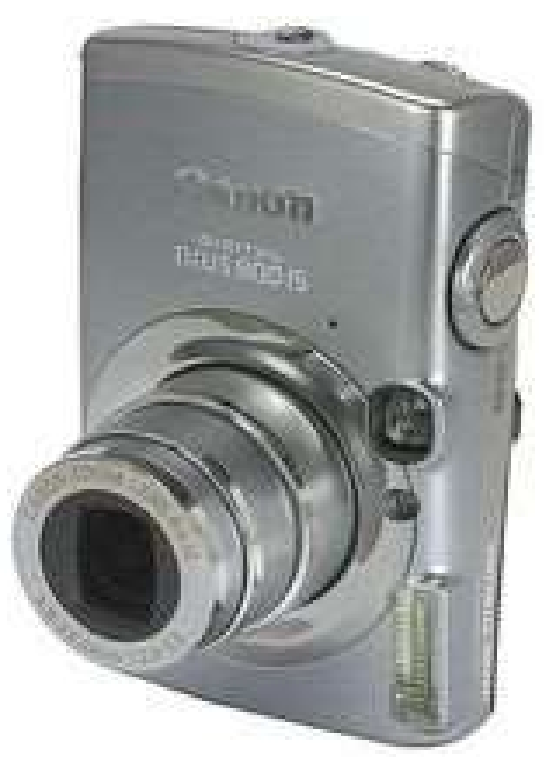

\section{PRODUCT X}

"While on a trip abroad, in a shop / on Internet / to a market, you are proposed an Eastpak backpack for a price of $16.66 € / 49.99 €$. It's $a$ genuine product / a counterfeit"

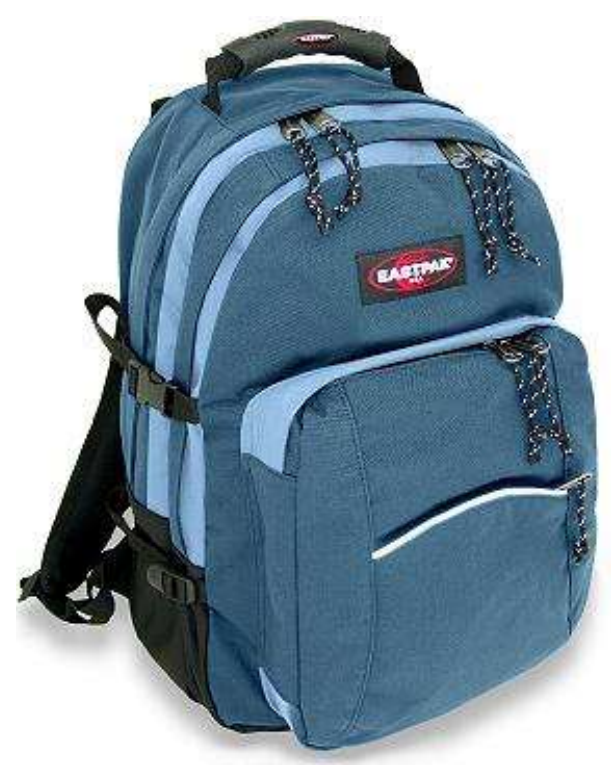

